\title{
LA POLÍTICA DEL MAESTRO IGNORANTE: LA LECCIÓN DE RANCIÈRE
}

\author{
Alejandro A. Cerletti \\ Il faut que je vous apprenne que je n'ai rien \\ à vous apprendre. \\ (Joseph Jacotot) \\ L'égalité ne se donne ni ne se revendique, \\ elle se pratique, elle se vérifie.
}

(Jacques Rancière)

\begin{abstract}
RESUMEN: El maestro ignorante, de Jacques Rancière, es un sagaz libro de filosofía que, a partir de la exhumación de un personaje singular de la historia de la educación - Joseph Jacotot -, problematiza una cuestión política fundamental: la igualdad. Educación, filosofía y política tejen la trama compleja de este texto altisonante y provocador. En este trabajo se intentará mostrar cómo Rancière conmueve los cimientos de las interpretaciones que hacen de la igualdad el punto de llegada de las políticas supuestamente emancipadoras y en qué medida queda abierta la cuestión de cómo llevar adelante una política igualitaria, no sólo en la educación sino también, y sobre todo, en general.
\end{abstract}

Palabras clave: Igualdad. Explicación. Política. Educación. Filosofía.

\section{THE IGNORANT SCHOOLMASTER'S POLICY: THE LESSON OF RANCIÈRE}

ABSTRACT: Jacques Ranciere's The ignorant schoolmaster is a sagacious book of philosophy that, based on the exhumation of a singular character in the history of education - Joseph Jacotot problematizes the fundamental political issue of equality. Education, philosophy and politics are woven into the complex plot of this lofty

Professor del Departamento de Filosofía de la Universidad de Buenos Aires. E-mail: acerlett@filo.uba.ar 
and provocative text. This paper aims to show how Rancière disturbs the interpretive foundations which presume to make of equality the point of arrival of a pretentiously emancipatory politics, and to what extent the question remains open of how to develop an egalitarian policy - not just in the realms of education but more generally.

Key words: Equality. Explanation. Politics. Education. Philosophy.

E

n el cruce de la educación institucionalizada y la acción política progresista se ha afirmado que la educación tendría como una de sus tareas fundamentales intentar paliar o mitigar las contradicciones de clase (o de género, de raza, de religión, u otras) propias de nuestras sociedades. La prédica liberal ha insistido con que la escuela debería funcionar como reguladora de las desigualdades sociales, garantizando mecanismos o estrategias que converjan hacia la igualdad de oportunidades. Los ideales fundacionales de la Ilustración, que con diversos matices llegan hasta nuestro presente, colocaban a la adquisición de conocimientos como la llave maestra para la consecución de la libertad del hombre. Correspondería a la instrucción pública extender tal beneficio a todos, sin diferencias de origen. Estas diversas consideraciones comparten el supuesto de que la institución educativa tendría la responsabilidad política de hacer algo por igualar lo que se presentaría, de hecho, como desigual.

El maestro ignorante, de Jacques Rancière, es un sagaz libro de filosofía que, a partir de la exhumación de un personaje singular de la historia de la educación - Joseph Jacotot -, cala hondo en una cuestión política fundamental: la igualdad. Educación, filosofía y política tejen entonces la trama compleja de este texto altisonante y provocador. En las páginas que siguen intentaré mostrar cómo Rancière conmueve los cimientos de las interpretaciones que hacen de la igualdad el punto de llegada de las políticas supuestamente emancipadoras y en qué medida queda abierta la cuestión de cómo llevar adelante una política igualitaria, no sólo en la educación sino también, y sobre todo, en general.

El maestro ignorante se desarrolla en un doble registro, en dos recorridos paralelos que se entrecruzan y realimentan. En el primero, el relato se construye sobre la figura de Joseph Jacotot y su experiencia personal de enseñanza en los albores del siglo XIX, profundamente convulsionada por una serie de circunstancias azarosas que motivaron un cambio tajante en su mirada sobre la educación tradicional. El segundo, se despliega a partir de la apropiación política que hace Rancière de aquella experiencia, en una suerte de contrapunto constante. En este 
doble movimiento, el libro va sobreimprimiendo a la descripción de una cuestión básicamente pedagógica la construcción de un problema eminentemente político, verdadero núcleo propositivo de la obra.

No deja de sorprender cómo El maestro ignorante, ya desde las primeras páginas, dirige un ataque demoledor sobre un recurso clásico y señero de toda educación: la explicación. De manera abrupta, vemos que la explicación pasa de ser aquella herramienta privilegiada con la que los maestros, desinteresadamente, han intentado llevar a sus alumnos hacia el conocimiento y la cultura, a convertirse en un arma sutil de imposición y dominación. Una serie de circunstancias puntuales de su experiencia concreta de enseñar le hicieron comprender a Jacotot que la "explicación" (es decir, la conducción de los alumnos, por etapas, desde la ignorancia hacia el saber), contrariamente a lo que sostenía la pedagogía - y él mismo pensaba hasta entonces -, no era el vehículo preclaro e imprescindible del magisterio; que era posible construir otra relación entre maestros y alumnos que la tradicional vertical, organizada a partir del que supuestamente sabe y el que no. Esta conmoción originada en la práctica misma pasó a ser el punto de quiebre de toda una concepción de la enseñanza y transformó la vida de Jacotot en un esforzado intento por desplegar hasta sus últimas consecuencias la novedad que había vislumbrado. Rancière se detiene cuidadosamente en este proceso y desarrolla, a su vez, en toda su magnitud, las consecuencias políticas que este quiebre supone.

En la interpretación Jacotot-Rancière, la explicación cumple una tarea fundamentalmente regulativa. En la medida en que divide el mundo en dos, separando a los que saben de los que no - los que "explican" de los que escuchan y "aprenden" -, instaura una segmentación que es mucho más significativa que una mera distinción de dominios de saberes. Toda la enseñanza clásica se apoya en esta idea supuestamente neutral de la explicación-transmisión, cuya matriz sostiene, a grandes rasgos, que hay algo (un conocimiento, una destreza) que alguien tiene - el maestro - y se lo transmite, por medio de una explicación, a alguien que no lo tiene, el alumno. El que no sabe irá aprendiendo de a poco y con el tiempo adquirirá los saberes de que carecía. Pero el reconocimiento de esta distinción entre los que saben y los que no, que es inherente a la existencia misma de cualquier magisterio, no sólo define la relación que cada uno tiene con los conocimientos sino que, y esto es lo más importante, demarca una serie de estamentos. En efecto, tomar conciencia de la segmentación que produce el dominio de ciertos saberes hace que cada uno internalice el lugar que ocupa y vea 
que la posibilidad de ascender viene ligada a la subordinación - en principio, intelectual - a un explicador. Si uno pudiera hacerlo por sí mismo no sería necesario el maestro. Para Jacotot, la institución educativa tiene como función reproducir esta distinción jerárquica porque de ella justamente vive, es su condición de posibilidad. El maestro administra, en nombre del estado, un segmento de poder. Él controla la distancia que hay entre lo que se debe enseñar y lo aprendido, entre lo enseñable y la comprensión de lo enseñado. Constituye la supervisión y garantía de la eficiencia de la transmisión. El que explica algo y luego controla la fidelidad de lo "aprendido" es para Jacotot un "embrutecedor”, alguien que no emancipa sino que instala al otro en un mundo de rangos, consolidado y natural.

La experiencia inédita vivida por Jacotot le hizo constatar que es posible aprender sin un maestro explicador, que si alguien quiere aprender puede ser capaz de disponer las relaciones con el otro de una manera original y propia. Aprender sin un maestro explicador no quiere decir, sin embargo, que se prescinda de todo maestro. Pero ¿qué quiere decir que pueda no haber un explicador y que de todos modos se pueda aprender de un maestro? ¿Qué enseña un maestro que emancipa, a diferencia de otro que explica y, por lo tanto, embrutece? ¿En qué consiste este magisterio diferente? Por lo pronto, para Jacotot es preciso separar las dos funciones que la práctica del maestro explicador une: la del conocedor o especialista en un saber y la del que enseña. ¿Qué podría significar entonces enseñar otra cosa que un saber, ser algo distinto del conocedor que transmite su dominio? No se tratará de enseñar el propio saber (en rigor, ni siquiera hay que tenerlo: esa es, justamente, la escandalosa posibilidad del maestro "ignorante") sino de hacer explícito que el otro es capaz de aprender lo que quiera. Lo que se enseña cuando se emancipa es a usar la propia inteligencia. La función del maestro será plantear al alumno un desafío del que no pueda salir más que por sí mismo. Es interrogar como un igual y no como un conocedor, que ya sabe todas las respuestas. El que enseña emancipando sabe que él también está aprendiendo y las respuestas del otro son nuevas preguntas para él. La palabra circula entre todos y no en una sola dirección. El Telémaco de Fénelon, verdadera herramienta-motor del "método" Jacotot, permitía decir a cada uno lo que pensaba. Permitía que cada uno hable, no como maestro o alumno, sino como hombre o mujer. Es decir, no como aquel que es examinado en vista de una evaluación sino como aquel de quien interesa lo que pueda decir. No se trata de explicar lo que los científicos, los artistas o los filósofos dicen o hacen, sino de ser, en alguna forma, científicos, artistas o filósofos. 
¿Cuál es la lectura política que puede hacerse de este "antimagisterio" de Jacotot, quien no se cansaba de repetir que no tenía nada (ningún "contenido" en especial) que enseñar a sus alumnos? La posibilidad de emancipación en el enseñar está ligada, para Jacotot, a la potencialidad de un triple cuestionamiento, que es un llamado libertario dirigido a la inteligencia, y un imperativo radical, dirigido a la voluntad. El maestro no debe dejar de preguntar: "y tú... ¿qué ves?, ¿qué piensas?, ¿qué harías?". Las respuestas, entonces, dejarán de ser un secreto que atesora el maestro para transformarse en una conquista, de cada alumno, sobre los saberes, sobre el mundo y sobre sí mismo. El único imperativo que el maestro debe sostener con tenacidad frente a un alumno es "itú puedes!". Partiendo de esta consigna, que potencia las posibilidades de cada uno, junto a los tres interrogantes mencionados, es posible desplazar la cuestión educativa hacia la política y evaluar sus consecuencias. En efecto, alguien que no se somete a un orden jerárquico, construido a partir de desigualdades de inteligencia u otra referencia, alguien que no se ve como inferior sino que reconoce y valora su propia capacidad, y se sostiene en su tenacidad, podrá emanciparse. Un obrero (o un campesino, un artesano o cualquiera) se emancipará intelectualmente "si piensa en lo que él es y en lo que hace dentro del orden social" (Rancière, 2002, p. 57). Podríamos decir que, en un sentido estricto, recién entonces será un sujeto, alguien que se conoce a sí mismo como viajero intelectual, como alguien que piensa y puede actuar en consecuencia. Como alguien que se interroga y que puede interrogar a los que supuestamente saben y, sobre todo, a los que supuestamente saben y además gobiernan. En términos de Jacotot: "Toda la práctica de la enseñanza universal se resume en la pregunta: $i y$ tú, qué piensas? Todo su poder radica en la conciencia de emancipación que ella actualiza en el maestro y suscita en el alumno." (Rancière, 2002, p. 60). Si no se trata de transmitir conocimientos, entonces, ¿¿cualquiera podría ser un maestro emancipador? Efectivamente, siempre y cuando haga propios el triple cuestionamiento y el "tú puedes".

Esta condición de sostener la enseñanza y la emancipación en una singularidad - la construcción del camino próprio - tiene una derivación peculiar: la imposibilidad de institucionalizar un "método Jacotot". Esta consecuencia es catastrófica para quienes, por ejemplo, imaginan que la liberación de los hombres y las mujeres puede ser conducida por una política de estado, por "progresista" que ella sea. No es difícil entrever una veta anarquista en la médula del planteo político-pedagógico que Rancière realza de Jacotot: enseñar y aprender es un vínculo directo entre los individuos (sin mediaciones), la imposibilidad de institucionali- 
zación, la relación conflictiva con el estado, etc. Pero no es tan interesante la eventual perspectiva de desescolarización que podría derivarse del planteo general de Jacotot - ya que la intención de Rancière es más política que pedagógica - como la posibilidad de pensar, a partir de aquél, una política de nuevo cuño. En efecto, el movimiento que fuerza Rancière en la experiencia pedagógica de Jacotot, por un lado, deja al descubierto una de las paradojas de la institución educativa (y, más específicamente, del estado): qué es lo que impone o debe imponer (o sea, hasta dónde obliga) en nombre de la libertad. Lleva al centro de la escena los límites del ejercicio de la autoridad y la necesidad de sujeción (el estado a través de la escuela) frente a la constitución de sujetos (seres libres). Por otro lado, se nos advierte que no hay quien nos debe decir cómo son las cosas y qué es lo que habría que hacer; sólo se nos insiste en que somos capaces de pensar y hacer. La incapacidad de llegar a algo por uno mismo, en tanto ficción estructurante que se debía suponer para fundamentar la explicación, es la misma incapacidad que se debe suponer para hacer una política de delegación. En nombre de una incapacidad técnica u operativa (desconocimiento/imposibilidad de ejercer por uno mismo las decisiones) se justifica la necesidad de mediadores: los tecnócratas economicistas, los políticos “profesionales” etc. La paradoja del maestro emancipador es que emancipa sin constituirse ni en líder ni en guía, lo hace sólo apostando a que cada uno puede hacerlo. Se podría ir más lejos aún. La explicación no sería sólo el arma embrutecedora que emplean los pedagogos ingenuamente, sino la estructuración misma del orden social: la explicación dominante es la que "explica" - manifiesta o implícitamente - el porqué de la distribución de los rangos existentes y la necesidad de su sostenimiento para el beneficio común. Las distancias que la escuela (y el estado) pretende reducir son aquello de lo que vive y le da sentido, y en consecuencia, no deja de reproducir. En última instancia, se garantiza la integración del lazo social a partir de la integración pacífica de la masa, guiada por las élites instruidas. La tremenda osadía o pretensión de insinuar que se puede "enseñar lo que se ignora", mucho más que manifestar un absurdo didáctico, tiene una intencionalidad filosófica y política crucial. Expresa la potencia del pensamiento y la posibilidad que tienen todos de construir lo nuevo.

Ahora bien, nada de esto sería posible sin el supuesto constituyente de que todos somos iguales, que, en Rancière, presenta una radicalidad inédita. Pero ¿qué quiere decir y qué alcances tiene dicha afirmación?

A diferencia de los análisis usuales de la cuestión igualitaria en la que la igualdad termina siempre siendo un objetivo a conquistar, Rancière 
parte de, o postula, la igualdad, para luego extraer de esa apuesta todas las consecuencias que sea posible derivar. La igualdad no será entonces algo que está al final del camino, como una lejana meta a la que hay que llegar y respecto de la cual sólo importa discutir y evaluar los métodos para alcanzarla. Para Rancière, la igualdad es una afirmación sin más fundamentación que la decisión de hacerla y la voluntad de ser consecuentes con ella. En esta línea, ubicar la igualdad al comienzo define un punto de inicio para todas las acciones humanas y un pensamiento verdaderamente liberadores.

En Jacotot, el tema de la igualdad está focalizado en la igualdad de las inteligencias. Rancière hace pie en él, se sirve de él, y lo extiende a un plano general. En este movimiento podemos ver cómo el desplazamiento de lo pedagógico a lo político toma forma, una vez más. La decisión de partir de la igualdad, aunque no fundada, tiene sin embargo una serie de comentarios o ilustraciones que acercan una suerte de justificación. En efecto, Rancière se detiene en discutir la trivial constatación empírica de que lo que hay es la desigualdad. De hecho, por todos lados no se vería más que desigualdad de inteligencias, o desigualdad a secas. Qué más natural que comprobar la evidencia, lo que cualquiera podría corroborar: que hay inteligentes y brutos, capaces e incapaces, espíritus abiertos y cerebros obtusos. Unos pasan mejor los exámenes que otros; unos progresan, otros repiten, ya sean alumnos del mismo origen social, cultural etc., o diferente. Unos saben, otros no. Unos pueden, otros no. Pero ¿qué se puede extraer en nombre de la política o en favor de la justicia verificando que todos somos diferentes? ¿Acaso no se puede afirmar también que es evidente la igualdad del amo y el siervo o del dominador y el dominado, en la medida en "que es evidente" que los segundos deben "comprender" las órdenes de los primeros, para obedecerlas? ¿No se trata de la misma inteligencia la que los hace situarse en la misma estructura de dominación? Para Rancière, quien quiere proceder a partir de la desigualdad debe presuponer la igualdad y en esto apoya la decisión que guía el libro.

La educación y la política no pueden partir de la desigualdad y tratar de anularla con acciones correctivas - educativas o políticas -, que procuren hacer iguales de los desiguales. Quien parte de una desigualdad que entiende de hecho, evidentemente la admite. Esto significa que reconoce que o bien hay desiguales a él (inferiores) y él aspira igualarlos (haciendo lo posible por "ascender" a los inferiores), o bien hay desiguales a él (superiores) que él debe esforzarse en igualar, pero con la ayuda de los superiores (ya que de no ser así, evidentemente no serían 
sus superiores y podría bastarse a sí mismo). En cualquiera de los dos casos, lo que domina - y es la matriz de la lectura política que hace $E l$ maestro ignorante -, es el menosprecio, ya sea del otro o de uno mismo. Es querer fundar todo intento de acción en la impotencia, en la debilidad o en lo peor de cada uno.

Tampoco se trataría, por cierto, de intentar realizar una comprobación científica empírica de la desigualdad de las inteligencias (que en el fondo no será más que una petición de principio, ya que lo que se encontrará es la desigualdad que se presupuso), o de intentar constatar que esto sea siquiera posible (jamás se podría llegar a otra cosa que a constatar que todos somos diferentes), o, peor aún, de intentar cuantificar cuán diferentes somos. Pero, ¿qué podría significar "probar" que dos inteligencias son iguales, o diferentes en tal número? En definitiva, la inteligencia se puede reconocer por sus efectos y la exploración de los efectos de un postulado igualitario es, para Rancière, mucho más significativo que partir de una evidente desigualdad.

Lo que interesa a Rancière es descubrir la potencialidad de todo hombre o mujer cuando se considera igual a los demás y considera a todos los hombres iguales a él. La voluntad será la vuelta sobre sí del ser que razona, que se reconoce con capacidad para pensar y actuar. El reconocimiento de la igualdad horizontaliza las relaciones de poder y ubica el protagonismo en cada uno de nosotros. Es una manera de establecer relaciones entre los humanos en las que a todos sin excepción se les reconoce la dignidad de la palabra (la palabra es lo que comparten, por ejemplo, el rico y el pobre, es lo que los hace iguales). Lo que embrutece a una persona no es su falta de instrucción sino la creencia en la inferioridad de su inteligencia, y lo que embrutece a los "inferiores" embrutece, al mismo tiempo, a los "superiores".

Lo verdaderamente emancipador no será entonces el recorrido o el camino hacia el logro de una igualdad (que, en definitiva nunca se concreta), sino el reconocimiento del principio. La igualdad no se da ni se reivindica, ella se practica, nos enseña Rancière. Y Jacotot nos muestra que el más "ignorante" sabe también muchas cosas y en eso debe fundarse toda enseñanza. Instruir será entonces: o embrutecer - es decir, confirmar una incapacidad, pretendiendo reducir la distancia al no saber - o emancipar, esto es, forzar una capacidad que se ignora o niega que se tiene para extraer de ello todas las consecuencias.

El siglo que acaba de concluir ha visto cómo ha ido cambiando la valoración del lugar y la función que corresponde a maestros y profesores. Se ha pasado de enaltecerlos, desde su papel casi santo de misioneros 
educativos o liberadores sociales, a denunciarlos como poco menos que instrumentos perversos de la reproducción social e ideológica del capital. Con mucha agudeza, Rancière pone el centro de atención en otro lugar y descoloca aquella contraposición. En este cambio de perspectiva, los maestros (y todos los hombres y las mujeres en general) no liberarán o someterán por su sola función en el diseño institucional de un estado, sino que lo harán a partir de sus decisiones en cuanto a la relación que establecen con los demás. La acción emancipadora será consecuencia de sostenerse en el postulado de la igualdad entre los seres humanos, y, a partir de esta decisión, se abrirá un mundo de posibilidades inéditas en la que la posesión de saberes no será el fundamento velado de las jerarquizaciones. Éste es el mensaje que El maestro ignorante nos da. Pero también abre las puertas a otros desafíos.

A su manera, el libro de Rancière rompe, en un sentido general, con la noción de "víctima" (del sistema, de las condiciones de producción y reproducción, de la pobreza estructural, de la globalización etc.), ya que la supuesta víctima es alguien que piensa y decide, y no un mero cuerpo que debe ser alimentado o un ignorante que debe ser educado. La combinación conceptual reconocimiento de la desigualdad en el origen - victima no puede llevar mucho más lejos que a la caridad, al sentimiento piadoso de la beneficencia. Y esto es así porque no se considera al otro un igual sino un inferior que debe ser ayudado. Por el contrario, el otro es para Rancière alguien que piensa y en el diálogo igualitario de las inteligencias es que puede ponerse de manifiesto que un "ignorante" puede llegar a ser un emancipador y un sabio, un embrutecedor. Podemos sacar una conclusión quizás para muchos sorprendente: la igualdad no depende de lo social (ni es siquiera el resultado de una acción justa), sino de una decisión y de ser coherente con ella. Pero no es todo. El maestro ignorante deja vislumbrar también una idea singular: la igualdad está excluida del funcionamiento normal de todo orden social, pero es, a su vez, su justificación y objetivo (se la pone afuera, y es, en última instancia, inalcanzable). El contrapunto en la educación es también significativo: siempre hay algo que callar para que la educación sea posible.

Jacotot constituyó una disrupción, un ruido molesto en el buen orden del estado de cosas imperante, imposible de ser oído desde la normalidad. El desafío que asume Rancière es ser consecuente con la radicalidad de aquella novedad, en principio pedagógica, para comenzar a recorrer caminos políticos inéditos. El maestro ignorante pone en el centro de la atención la tensión que soporta la educación como reproducción de lo que hay y la posibilidad de aparición de lo 
nuevo. En última instancia, tematiza qué significa que haya, en un sentido estricto, "sujetos" de la educación, o mejor, "sujetos" de $s u$ educación. Pero también, y quizás sobre todo, que haya sujetos políticos.

Recebido e aprovado em fevereiro de 2003.

Referencia bibliográfica

RANCIÈRE, J. O mestre ignorante. Cinco liçōes sobre a emancipação intelectual. Trad. Lílian do Valle. Belo Horizonte: Autêntica, 2002. (Série: Educação. Experiência e sentido). 